\title{
建筑施工安全管理面临的问题与对策研究
}

\author{
刘坤
}

陕西建工安装集团有限公司，陕西西安 710003

[摘要] 安全管理已经成为建筑工程管理工作中的重点, 要想保证工程可以顺利开展应充分做好安全管理工作。假如安全管理 工作不到位不仅会给施工进度、质量、人员等带来损失同时也会使企业形象受损，因此在施工过程中应进一步强化安全管理 工作, 提升安全管理工作水平。在对安全管理工作中的问题进行分析后应制定出更具针对性的管理措施, 为工程建设人员创 建安全的工作环境, 确保建筑行业稳定发展。

[关键词]建筑施工; 安全管理; 问题; 对策

DOI：10.33142/ec.v4i4.3609 中图分类号：TU714 文献标识码：A

\section{Problems and Countermeasures of Construction Safety Management}

\author{
LIU Kun
}

Shaanxi Construction and Installation Group Co., Ltd., Xi'an, Shaanxi, 710003, China

\begin{abstract}
Safety management has become the focus of construction project management. In order to ensure the smooth development of the project, safety management should be fully done. If the safety management is not in place, it will not only bring losses to the construction progress, quality and personnel, but also damage the corporate image. Therefore, in the construction process, we should further strengthen the safety management and improve the level of safety management. After analyzing the problems in safety management, we should formulate more targeted management measures to create a safe working environment for construction personnel and ensure stable development of construction industry.
\end{abstract}

Keywords: construction; safety management; problems; countermeasures

\section{1 安全管理工作的重要性}

安全管理工作与建筑工程整体工作顺利进行有着直接的关系。首先应对建筑工程安全管理工作进行规范并将其贯 穿到工程中的各项工作中，主要包括人员管理、材料设备管理等方面。不断强化各项工作监管力度，从而可以对工程 建设过程中的问题进行及时排除、梳理并可以对施工过程中的风险进行识别, 通过有效的分析制定出安全管理及风险 防范措施, 从而提高建筑工程安全管理效果。同时建筑企业安全管理工作也会给招投标项目获得、企业经济效益带来 一定影响。在进行招投标工作时建筑企业应确保自身实力并可以科学合理的采用先进的施工技术及设备并保证安全管 理机制的科学性与实用性, 从而确保整体工程可以顺利开展。如果在施工过程中产生安全问题不仅会增加建设成本, 严重的话会危机到施工人员的生命财产安全, 给企业整体发展带来不良影响。因此建筑企业要想得到良好的发展应强 化安全管理工作并通过有效的安全管理工作降低建设过程中的风险并树立企业在社会中的良好形象，提升企业在建筑 市场中的竞争力 ${ }^{[1]}$ 。

\section{2 安全管理中的不足}

\section{1 安全管理制度不健全}

建筑工程安全管理工作应全面落实国家标准及规范, 通过此来保证安全管理工作效率与质量。但是还有很大一部 分施工企业并没有将安全管理制度进行落实, 无形中增加了安全事故的发生率。安全管理制度多是从宏观角度并没有 对安全管理工作进行细化, 企业在制定安全管理制度时也多将施工情况作为依据, 重视度不足就无法保证安全管理制 度的全面性与完善性, 从而增加了建筑工程安全风险。此外, 还有一部分施工企业并没有构建安全管理系统, 将更多 的精力放在施工进度管理方面, 安全管理工作认识度较低, 再加之没有设立专门的安全监管部门及人员, 导致安全监 管工作不到位; 即使企业中设置了安全管理部门但是没有将管理责任进行落实, 安全管理人员安全管理意识差, 在管 理过程中多存在侥幸心理也增加了安全事故发生几率, 无法保证建筑工程安全管理效率及管理质量。安全管理责任落 实不到位, 当发生安全事故时无法在第一时间进行处理, 或是在处理过程中多依赖以往经验, 最终导致管理失效, 无 
法对安全事故进行控制, 导致问题扩大，给工程整体建设带来不利的影响。

\section{2 安全管理意识较低}

无论是哪个行业都应将安全管理放在首位, 建筑行业也不例外, 要想保证工程可以顺利进行应充分做好安全管理 工作。但是现阶段在进行安全管理工作时管理意识薄弱的现象比较常见, 这样就违背了安全管理工作的初衷。一大部 分施工企业认为安保部门是安全管理工作的主要部门, 认为只要安保人员在施工现场巡逻就可以, 但是此种方式流动 性较强, 无法实时掌控现场变化, 可见将安全管理工作交由安保部门进行管理是非常不科学的, 也无法保证安全管理 工作效率。此外, 一些企业虽然有专门的安全管理人员, 但是管理意识薄弱, 专业能力不强无法及时发现及处理安全 问题。同时还有一部分施工企业将管理重点放在成本控制及经济效益提高方面, 所聘用的施工人员可以接受高强度的 劳动但专业知识方面有限, 所以无法全面认识到安全管理工作的重要性, 施工时多依靠原有经验, 操作不规范现象比 较常见。再加之这部分人员流动性相对较大, 即使进行了安全培训也无法在短期内得到良好的效果, 导致安全管理工 作失效，这也是建筑工程安全管理中亟待解决的问题之一 ${ }^{[2]}$ 。

\section{3 无法做到安全管理工作精细化}

建筑工程中安全管理是重中之重, 其不仅与建筑企业发展有着直接的关系, 更关联到施工现场每名工作人员的人 身安全, 即使其中细小的环节出现问题也会导致大的安全事故。在进行建筑工程安全管理过程中应融入精细化管理理 念, 利用精细化管理理念可以实现安全管理全方位、全面化、精细化并可以使安全管理目标更加明确, 同时可以保证 安全管理工作内容更符合工程要求且可以使安全监管工作更加明确, 保证建筑工程管理的整体性与系统性。但是现阶 段在进行安全管理工作时并没有将精细化管理理念进行落实, 还有很多工程在施工时为了减少成本对安全管理投入进 行了限制, 从而可以节省资金投入量。例如在进行安全防护用品购买时会减少资金投入量，反而去选择一些质量差、 不达标但价格低廉的防护用品, 当这些防护用品在使用后不仅无法保证施工安全, 当有安全事故发生时无法起到保护 作用, 反而带来更大的隐患, 最终也无法保证企业经济效益。同时管理人员没有及时将老化或坏损的安全防护用品进 行更换, 此种情况下也无法起到防护作用。此外, 施工现场中一些危险区域中并没有设置安全警示牌, 人员可以自由 行走, 施工现场中的设备摆放不固定, 最终导致安全事故的发生。

\section{3 安全问题处理措施}

\section{1 对管理机制进行完善}

（1）在建筑施工过程中, 企业上级管理人员要增强建筑工程项目施工人员和安全管理人员的安全意识, 并定期开 展安全意识培训工作; （2）建筑企业要根据企业的实际施工情况和社会发展状况, 制定符合企业发展方向的安全管理 制度, 并确保所有工作人员严格按照安全管理制度开展建筑施工工作。在建筑工程项目施工过程中, 企业可以制定激 励制度和人才招聘制度, 确保招聘的工作人员具有较高的施工安全意识。与此同时, 激励制度的建立能有效提高工作 人员工作的积极性，确保安全管理工作落到实处。

\section{2 设置安全施工管理目标}

建筑工程施工过程中安全管理人员应先设置安全管理工作目标, 工程施工目标是开展安全管理工作的重要标准。 在进行施工安全管理目标设定时安全管理人员应对施工安全管理中的动态性、长久性及复杂性等进行综合考虑, 并根 据企业建筑工程施工要求和国家对建筑工程的建设要求, 制定符合工程项目的施工目标。在建筑工程施工过程中, 施 工人员和安全管理人员要严格依据进行施工组织及施工方设计, 并加强施工安全管理工作的开展, 有效实现建筑施工 安全管理目标 ${ }^{[3]}$ 。

\section{3 加强现场巡查}

在建筑施工过程中, 监理单位发挥着重要的安全管理监督作用。就当下而言, 很多监理单位在监管权利行使方面 存在较大的弊端, 无法及时发现建筑工程施工过程中存在的安全隐患, 无法保证建筑施工安全管理工作的有效开展。 针对这种情况, 企业应当加强监理单位的改革创新, 避免监理单位和施工单位产生利益关系, 无法保证建筑施工安全 管理工作的顺利开展。在建筑施工安全管理工作开展过程中, 建筑企业监理单位要对施工现场技术人员的操作行为进 行规范和监督, 避免因技术人员安全意识薄弱, 施工某一环节不符合要求, 最终发生安全事件。例如, 当发现技术人 员未佩戴安全帽进入施工现场时, 监理单位人员要及时提醒, 并要求技术人员返回营地戴上安全帽, 才能进入施工现 场。图 1 为建筑施工现场图。 


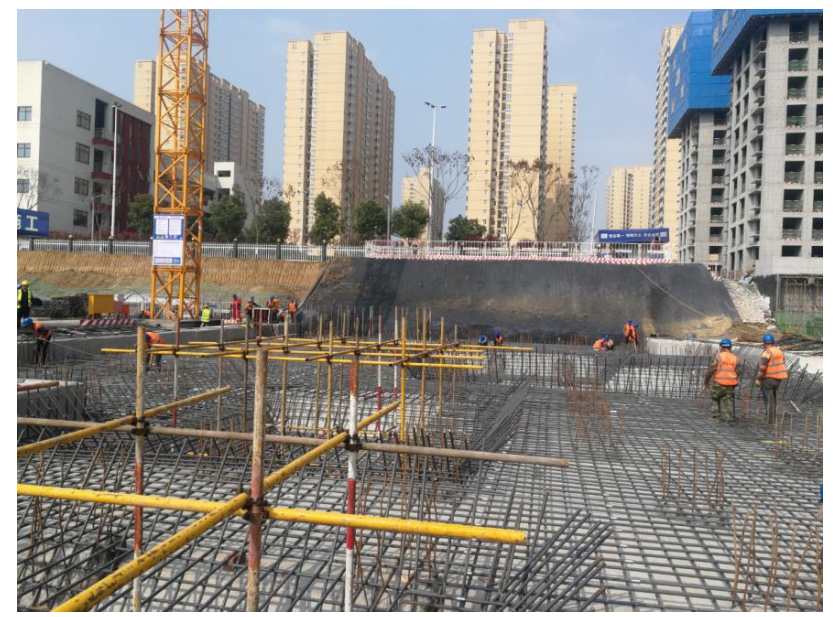

图 1 建筑施工现场

\section{4 建立健全奖惩制度}

不同的建筑工程对安全管理工作要求也有一定的区别, 因此要想保证安全管理工作效率应建立起奖惩制度, 通过 奖惩制度激发出工作人员的积极性并提高安全意识, 同时可以有效降低安全事故的发生率。利用奖惩制度对表现积极 的人员可以给予精神或物质方面的奖励, 利用奖励方式给工作人员以肯定。同时也可以召开表彰大会, 树立榜样, 利 用榜样的精神进一步提高安全管理工作实效性。对表现不足的人员也应根据奖惩制度给予一定的惩罚, 例如可以采用 通报批评或罚款方式, 惩罚并不是最终的目的, 而是希望工作人员可以通过惩罚来提高安全意识并在工作中遵守安全 规范, 同时也可以给其他工作人员以警示, 有效降低安全事故的发生率。此外, 当有安全事故发生时安全管理部门应 及时跟进并对施工发生原因进行调查, 在明确安全事故发生原因后再进行下一项工作。当发生安全事故后安全管理部 门还应做好总结与反思工作, 积累经验, 这样既可以有效避免安全事故发生率, 即使是发生安全事故也可以在第一时 间进行处理，将事态进行控制，从而保证工程可以顺利开展。

\section{5 对安全管理工作方式进行创新}

建筑企业在进行安全管理的过程中还应充分了解建筑行业变化情况, 实现同步。利用先进的技术对安全风险进行 识别、防控及管理。例如, 可以使用计算机技术构建建筑工程安全管理三维模型并对各施工环节可能产生的安全隐患 进行识别、分析。同时在进行建筑工程安全管理时还应了解工程特点及要求, 并对可能给安全管理工作带来影响因素 进行总结, 从而选择有效的管控方式并制定出相应的管理措施。此外, 制定安全事故预警体系, 对可能发生的安全事 故进行预判, 这样可以提升安全管理人员对临时事件的把控能力并提高解决问题的能力, 最大限度降低因安全事故所 带来的损失，在保证人身安全的基础上确保企业经济效益的提升。

\section{4 结束语}

总的来说, 建筑行业在社会经济发展中起到了重要的作用, 而且建筑行业整体发展相对平稳, 整体发展态势良好。 建筑工程管理工作具有较强的综合性且对管理人员的专业性有着较高的要求。在进行管理工作过程中既需要有健全的 管理体系同时还应对管理模式进行不断的创新, 从而实现建筑工程管理目标。而在建筑工程管理工作中安全管理又是 其中的重点, 其与工程建设整体水平有着直接的关系。在进行安全管理过程中应不断提高施工人员的认知度并将精细 化管理理念引入到安全管理工作中, 通过有效的安全管理提高企业经济性效益, 同时为建筑企业稳定发展提供有力的 支持, 更好的促进整体行业发展 ${ }^{[4]}$ 。

\section{[参考文献]}

[1]彭玉龙,刘海峰.浅析进一步强化建筑施工安全管理的措施 [J].砖瓦, 2020 (8): 96-97.

[2]许强.建筑工程施工过程中安全管理问题和对策解析 [J]. 产业创新研究, 2020(14) : 49-50.

[3]任琪. 当前建筑施工安全管理工作中存在的问题及对策 [J].中小企业管理与科技 (下旬刊), 2020(7): 9-10.

[4]黄斌。建筑施工现场安全管理存在的问题及对策研究 [J].住宅与房地产, 2020(18): 144 .

作者简介: 刘坤 (1989-) 男, 西安石油大学, 本科, 安全工程专业, 陕西建工安装集团有限公司, 注册安全工程师。 